\title{
Introducing Sociolinguistics
}

\section{Acheoah John Emike a, Abdullahi Sanni b, Margaret Nonyerem Agu c, Ayoola Moses Olusanya d}

\footnotetext{
${ }^{a}, b$ Department of European Languages, Federal University Birnin-Kebbi, Kebbi State, Nigeria

${ }^{c}$ Department of English, Ibrahim Badamasi Babangida University, Lapai, Niger State, Nigeria

d Department of English, Bamidele Olumilua University of Education Science and Technology, Ikere-Ekiti, Ekiti State, Nigeria

a actualemike@gmail.com
} 


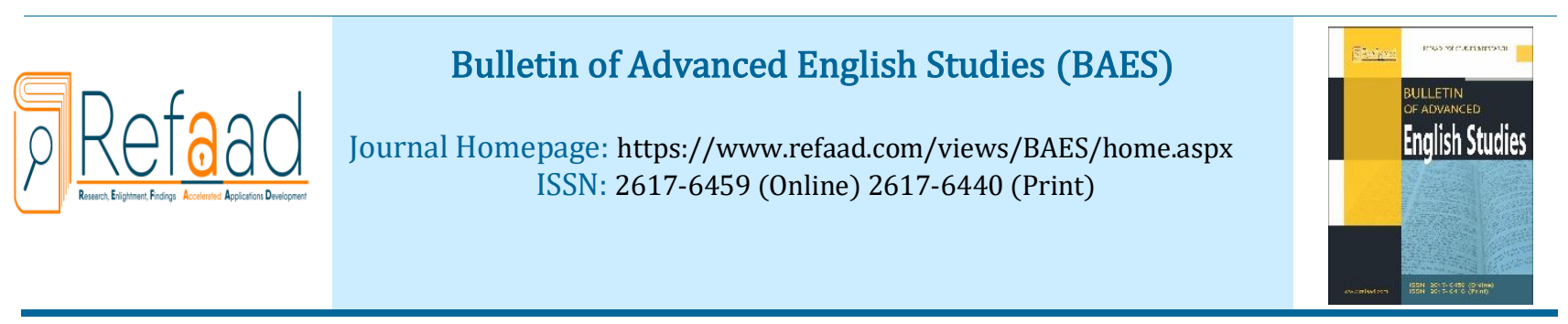

\title{
Introducing Sociolinguistics
}

\author{
Acheoah John Emike 1a, Abdullahi Sanni b, Margaret Nonyerem Agu c, Ayoola Moses Olusanya d \\ a,b Department of European Languages, Federal University Birnin-Kebbi, Kebbi State, Nigeria \\ c Department of English, Ibrahim Badamasi Babangida University, Lapai, Niger State, Nigeria \\ d Department of English, Bamidele Olumilua University of Education Science and Technology, Ikere-Ekiti, Ekiti State, \\ Nigeria
}

Abstract: This paper presents an overview of sociolinguistics by examining the fundamental concepts and issues therein. Research efforts in sociolinguistics focus on speakers and their exploration of language to cope with their daily communicative goals in society. The innate potential of language to cope with a wide range of phenomena to be expressed by speakers is incredible. Indeed, the repertoire of language is not exhaustive. Speakers express cultural norms, political issues, legal discourses, religious messages and scientific facts by using a linguistic system of communication - language. Sociolinguistics is the study of language and society. It elucidates the co-existence of different languages in society. Within a social structure, there are varieties of languages which contribute to the linguistic system and facilitate choice-making Sociolinguistics is about language and society. In this study, we introduce sociolinguistics by examining language (its definition, functions and varieties), society, speech community and other phenomena that are on the front-burner in the literature.

Keywords: Sociolinguistics; language; linguistics; society; speech community.

\footnotetext{
${ }^{1}$ Corresponding author

Email address: actualemike@gmail.com (Acheoah John Emike)

DOI: 10.31559/BAES2021.6.2.2
}

Received: 16 Oct 2021; Revised: 4 Nov 2021; Accepted 10 Nov 2021 


\section{Introduction}

Sociolinguistics investigates language and society. Language is the instrument for socializing with society, and the process shows that, indeed, human society operates as a system. Crystal (1971) notes that language is "the systematic conventional use of sounds, signs or written symbols in a human society for communication and selfexpression." This paper examines sociolinguistics as a field of language study with a view to elucidating critical phenomena that give the reader an instructive grasp of the subject: language attitudes, language contact, language shift, language planning, bilingualism and multilingualism among others.

\section{Sociolinguistics}

Different scholars attempt to define sociolinguistics. The various definitions reveal that sociolinguistics investigates "why", "how" and "where" human beings use language. Bosede Sotiloye (1992) gives an elaborative definition of sociolinguistics:

Sociolinguistics is a field of study which relates societal problems to linguistic/language problems. It answers the question: how do our social and cultural backgrounds affect our use of language? It is a branch of linguistics which tries to answer questions like who says what to whom, when, where how and why? One of the major aims of sociolinguistics is the study of the use of language in its social and cultural contexts. It studies the norms of the society at large and examines how the individual exploits his awareness of the society's norms in order to achieve particular effects.

Sociolinguistics is about speech community. Nigeria is an example of a large speech community which accommodates language varieties. Due to the concept of socialization, which is inevitable in a speech community, the individuals therein can shift from being monolinguals to becoming bilinguals or multilinguals. According to Abiodun Sofunke (1992), "sociolinguistics ... is another major area of applied linguistics. The sociolinguistic aspect of applied linguistics is concerned with issues which indicate the interaction between language and society. Society is in general divided along class and occupational lines, these divisions being in most cases reflected in language. The elucidation of the nature and use of these socially stratified speech forms is the business of sociolinguistics." Indeed, an incisive overview of sociolinguistics presupposes examining critical notions and phenomena in the literature.

\subsection{Language}

Language enables man to articulate his social nature in varied contexts. It is the instrument for conveying societal norms and values. Man's identity is indexed in/by language. According to Smith Jr. (1979, p. 9), language is "a learned, shared, and arbitrary system of vocal symbols through which human beings in the same speech community or sub-culture interact and hence communicate in terms of their common cultural experience and expectations."

\subsubsection{Functions of Language}

Language performs various functions in society. Although language scholars express the functions with differences in nomenclature, their submissions are quite similar. The functions of language include:

1. Interactive Function: Language is used for communication among human beings. Adeniran, cited in Ayodabo (2013, p. 139), asserts that "communication is thus a social function involving more than one living organism interacting where there are certain elements of behaviors to share. We must then perceive elements of behavior as ... being context (actions, information, concepts, emotions, etc.) as well as modes of sharing." This is the integrative (solidarity) function of language. Through the use of language, people can socialize. The works of speech act theorists such as Austin (1962), Searle (1969), among others, discuss speech act categories which are used to explain the interactive (communicative) functions of language: assertive, commissive (promising), directive (ordering, instructing), etc.

2. Domain-based Functions: Scholars hold the view that setting, participants (with varied age, gender, status and ethnicity) and topic constitute domain. Language is used in politics (policy-making, governance, administration, etc.), journalism and education (teaching, documentation). Domain-based functions of language capture the instrumental functions of language. The use of language in thinking and perception makes research in education possible. Bennett (1998) rightly posits that "language does serve as a tool for communication, but, in addition; it is a system of representation, for perception and thinking." In the educational domain, language is not only used for passing information or for documentation, but it is also used for publications and recruitment of people into jobs.

3. International Diplomacy: Language is used to strengthen bonds among nations of the world.

4. Lingua-franca: In a multilingual nation like Nigeria, a National Language (lingua franca) is used for:

- Nationism (for smooth running of a country);

- Nationalism (for national mobilization).

5. Symbol of Identity: People belong to one race or the other by virtue of their native language. According to Joshua Fishman (1968, pp. 81-82) "language and cultural identity are linked in three ways: indexically, 
symbolically and in a part-whole fashion. The symbolic link relates to identity, the sense of belonging to a community; the language stands for, or represents, the community of speaker."

Corroborating the idea that language indexes cultural identity, Adeniran, cited in Ayodabo, (2013, p.142) avers that "language is part of the cultural heritage that is handed down from a generation. It makes life experiences cumulative and makes cultural transmission possible." Commenting on the same concept, Kroskrity, cited in Wardhaugh R. and Janet M. Fuller (2015, p. 7) submits that "the term 'identity' has been used in a variety of ways in both the social sciences and lay speech. In the current society, identities are not fixed attributes of people or groups but are dynamically constructed aspects which emerge through discourse and social behavior. Although we do look at identities of individuals, what we are primarily concerned with is social identity: identity is defined as the linguistic construction of membership in one or more social groups or categories." ${ }^{2}$

\subsubsection{Varieties of Language}

In this section of the paper, we consider some varieties of English in a speech community.

\subsubsection{Pidgins and Creoles}

According to Wardhaugh R. and Janet M. Fuller (2015, p. 120), "Pidgins are conventionalized systems of communication, not idiosyncratic production. A pidgin can itself be a target language, that is, something which a speaker is trying to learn. However, both pidgins and interlanguage have a substrate influence (i.e., influence from the speaker's native language). Although it is often recognized that some similar linguistic and cognitive processes are at work in second language acquisition and pidginization, the distinction has been made between the development of an interlanguage spoken by an individual and the sociolinguistic process involving communication between various individuals speaking a second language which forms a pidgin." In addition, Winford (2003, p. 302) submits that "so-called pidginization is really a combination of different processes of change, including reduction and simplification of input materials, internal innovation, and regularization of structure, with L1 influence also playing a role." The literature makes it clear that Pidgin is a product of inter-regional trade relations. For example, Wardhaugh R. and Janet M. Fuller (2015, p. 123) submit that "Pidgin and creole languages are distributed mainly, though not exclusively, in the equatorial belt around the world, usually in places with direct or easy access to the oceans ... Consequently, they are found mainly in the Caribbean and around the north and east coasts of South America, around the coasts of Africa, particularly the west coast, and across the Indian and Pacific Oceans. They are fairly uncommon in the more extreme northern and southern areas of the world and in the interiors of continents. Their distribution appears to be fairly closely related to long-standing patterns of trade, including trade in slaves." Unlike Pidgins, Creoles emerge as a result of factors beyond trade; in this regard, language contact is a prominent factor. Two cultures can come into contact and evolve an artificial means of communication that facilitates trade. Citing Winford (200, p. 307), Wardhaugh R. and Janet M. Fuller (2015, p. 124) make it clear that "creoles constitute a motley assortment of contact vernaculars with different histories and lines of development, though of course they still have much in common ... [and] there are no structural characteristics that all creoles share ... [and] no structural criteria that can distinguish creoles from other types of language."

\subsubsection{Standard Variety}

This is an ideal variety of a language, regarded as the model in speech and writing. This explains why mutual intelligibility a crucial criterion for learners of the Standard Variety of English is. The speaker of Standard Nigerian English for example, should be able to produce segmental and suprasegmental phonemes that are internationally intelligible. However, the literature reports that mutual intelligibility cannot be objectively determined. It is not commonly used in casual discourses. It is suitable for instruction in schools and formal contexts. It is a model because it is void of regional features (ethnic stigmatizations). It is essentially a prestige dialect, spoken by the elite (educated people). It is relatively widespread in terms of expressiveness, regularity, logicality and complexity. This variety is actually hardly spoken by all the natives. The standard variety of a language is acceptable to all the native speakers as cutting across all regions where the language is spoken. It is usually codified and gives a sense of unity to the natives.

\subsubsection{Artificial Language}

This variety of language is created by man. Bosede Sotiloye cited in Ore Yusuf (1992, p. 144) notes that artificial variety of language "is usually created for a purpose, usually to serve as a unifying language in a multilingual speech community where there is no consensus as to which language should be chosen for a particular function. Examples: are Esperanto (made up of 5 vowels and 23 consonants) which is based mainly on European lexicon; Volapuk (with 8 vowels and 20 consonants) based largely on English and German; and Wazobia (based on Yoruba, Hausa and Igbo) ..."

\subsubsection{Educated variety}

This is perhaps, the most practical variety. It is easily identified. This variety is typically acquired through formal education and possesses non-regional features (peculiarities). The speakers of this variety do not demonstrate the same level of competence in the phonological features, but they all aim to acquire a proficiency level that is internationally intelligible regardless of ethnic backgrounds. The educated variety is divided into

\footnotetext{
${ }^{2}$ They also note that "our identities are fluid and we do not have a single identity but multiple levels of identity ... and sometimes even conflicting identities which emerge in different contexts."
} 
various variations: phonological, lexical (vocabulary), syntactic and graphological.

\subsubsection{Idiolect}

This refers to the peculiarities of individual speakers in terms of language habits (idiosyncratic features): voice quality, mannerisms, etc.

\subsubsection{Sociolect}

Sociolect: This is the speech variety that is peculiar to a particular social group within the society. For example, sociolinguistic variables such as age, social status and occupation produce speech peculiarities by certain individuals.

\subsubsection{Register}

Register: It is the stock of expressions restricted to certain occupations (professions) or domains. Below are examples:

Law: prosecute, convict, judgment, barrister

Medicine: epidemic, surgery, theatre, drug

Politics: parliament, election, minister, governance

Religion: church, sacrament, priest, sermon

Wardhaugh R. and Janet M. Fuller (2015, p. 52) submit that "the study of dialects is further complicated by the fact that speakers can adopt different styles and registers of speaking, and both spoken and written language can be seen as belonging to different genres of language. So while differences in dialect have to do with speakers and their regional or social identities, styles, registers, and genres have to do with different contexts of use. Although the terms style, registers, and genre have been used in different ways by different scholars, and there may be overlap between these three terms, we can delineate broad categories which differentiate them (Lee 2001). The term style is most often used to discuss differences in formality; register generally denotes specific ways of speaking associated with particular professions or social groups; and genre is understood as a set of co-occurring language features associated with particular frames ..." Goodwin and Alim (2010) is a study which shows how style and stance-taking work. The use of special modes of communication indexes solidarity, aggression, etc. Different fascinating perspectives abound in the literature on the definition of register. For example, Agha (2006, p. 24) submits that a register is "a linguistic repertoire that is associated, culture-internally, with particular social practices and with persons who engage in such practices."

\subsubsection{Dialect}

It is a regional variety of a standard language. According to Wardhaugh R. and Janet M. Fuller (2015, p. 38) "Regional variation in the way a language is spoken is likely to provide one of the easiest ways of observing variety in language. As you travel throughout a wide geographical area in which a language is spoken, and particularly if that language has been spoken in that area for many hundreds of years, you are almost certain to notice differences in pronunciation, in the choices and forms of words, and in syntax. There may even be very distinctive local colorings in the language which you notice as you move from one location to another. Such distinctive varieties are usually called regional dialects of the language." Indeed, dialects emerge from big languages in discrete aspects of languages, even when the differences are not so salient: vocabulary, structure and function. This implies that unlike the term "language", dialect can only exist in relation to a particular language where the dialect is logically a variant of the language.

\subsubsection{Ethnic Group}

When a group of people are from the same ethnic origin and are anchored by the belief in their identity. It is referred to as "ethnic group". Heller (2007) notes that the concepts of identity, along with those of community and language are instrumentalities of social cohesion (organizational cohesion). Scholars paraphrase the term "ethnic group" as nationalism (ethnic solidarity). The feeling of membership of a particular ethnic group is informed by the fact that such people have common ancestry and cultural values. Language is crucial in the definition of an ethnic group. Coulmas (1999) reports the commonly held view that language and ethnicity or nationality are synonymous concepts.

\subsubsection{Society (Speech Community)}

According to Bello, O. Rachael and Oni-Buraimoh, O. Olawunmi, (2017, p. 100) “Morgan's (2003) view is that a speech community does not simply focus on groups that speak the same language but rather that the concept takes as facts the notion that language represents, embodies, constraints and constitutes meaningful participation in society and culture. Morgan sees the study of the speech community as being central to the understanding of human language and meaning making because it is the product of prolonged interactions among those who operate within shared beliefs and value systems regarding their own culture, society and history as well as their communication with others. In his view, these interactions constitute the fundamental nature of human contact and the importance of language, discourse and verbal styles in the representation and negotiation of the relationships that ensue. Morgan goes further to submit that the concept of speech community (which a global language indexes) does not simply focus on groups that speak the same language but that it connotes that the common language represents, embodies, constructs and constitutes meaningful participation in a society and culture. Similarly, to Morgan, a homogenous community presupposes the existence of a mutually intelligible, symbolic and ideological 
communicative system among members." ${ }^{3}$ To understand the underpinnings of language use in any speech community, the norms of that society have to be understood. This view corroborates Wardhaugh R. and Janet M. Fuller (2015, p. 4) who state that "the linguistic behavior of individuals cannot be understood without knowledge of the communities that they belong to." In a similar submission, Wardhaugh R. and Janet M. Fuller, 2015, p. 11) posit that "... the relationship between language and culture was a deterministic one; the social categories we create and how we perceive events and actions are constrained by the language we speak. Different speakers will therefore experience the world differently ... as the languages they speak differ structurally. One claim is that if speakers of one language have certain words to describe things and speakers of another language lack similar words, then speakers of the first language will find it easier to talk about those things ..."

\section{Sociolinguistic Phenomena}

\subsection{Language Contact}

When two or more languages come into contact - as in immigrant situation, linguistic and cultural features of one language affects the other; this situation is known as language contact. Language contact inevitably produces effects on the languages concerned. For example, Omowumi Bode Steve Ekundayo cited in Ayodabo et al. (2016, p. 451) submits that "the contact and interaction of English with the Nigerian environment as well as the mother tongues (MT) and/or first languages (L1) of Nigerians often leads to language transfer and the emergence of interference features. Apart from this sociolinguistic interaction, the features of English in the mind of the learner interact and influence one another independent of the MT and L1 of Nigerians. Consequently, the psychosociolinguistic interaction of the languages in contact causes a new variety to emerge; a variety which blends the socio-cultural linguistic markers of the second language situation and the linguistic features of the languages in contact. Invariably, the variety becomes a fertile ground for research. Investigators then study it by adopting some methods, theories and terminologies like contrastive analysis, error analysis, language transfer, languages in contact, contact linguistics, transitional linguistics, interference, interlanguage ..." For more insights on language contact, see Martin Putz (1994) and Naklas Millen (1989).

\subsection{Language Pedagogy}

The teaching and learning of native and non-native languages via a wide range of processes and methods is known as language pedagogy. Crucial issues in language pedagogy include: setting for the teaching and learning process (formal or informal, native speaker setting, non-native speaker setting); the implications of the learners' age differences on the teaching and learning process. The literature is replete with teaching methods: Grammar Translation Method, Audio-Visual Method and Direct Method. Efficiency in the teaching and learning of language depends on the method applied towards acquiring mastery of four basic skills: reading, writing, speaking and comprehension in listening.

In language pedagogy, there are specified language skills to be taught as contained in the curriculum. Breen (1987, p. 23) submits that pedagogical task is "any structural learning endeavour which has a particular objective, appropriate content, a specified working procedure, and a range of work plans which have the overall purposes of facilitating language learning - from the complex and brief exercise type to more complex and lengthy activities such as group problem-solving or simulations and decision-making."

\subsection{Language Shift}

Language shift is common among immigrants. It is a situation in which a person's strong language gradually becomes weak because it is not frequently used. According to Stroud and Mpendukana (2009), the use of language indexes its value. A situation whereby a language is not frequently used could either culminate into language loss or retention. Harrison (2007, p. 7) posits that "language disappearance is an erosion or extinction of ideas, of ways of knowing and ways of talking about the world and human experience."

\subsection{Language Choice}

Choice making in the use of language is possible in multilingual speech communities, and it is motivated by several variables, part of which are the literary potential of a language and its economic might.

\subsection{Language Standardization (codification)}

This is the process whereby a government agency establishes a framework for promoting languages through codification (institutionalized spelling forms, pronunciation and grammar). Wardhaugh R. and Janet M. Fuller (2015, p. 34) submit that "standardization refers to the process by which a language has been codified in some way. That process usually involves the development of such things as grammars, spelling books, and dictionaries, and possibly a literature ... We can often associate specific items or events with standardization, for example, Whycliffe's

\footnotetext{
${ }^{3}$ In addition, Labove, cited in Wardhaugh R. and Janet M. Fuller (2015, p. 65) post that "the speech community is not defined by any marked agreement in the use of language elements, so much as by participation in a set of shared norms, these norms may be observed in overt types of evaluative behavior, and by the uniformity of abstract patterns of variation which are invariant in respect to particular levels of usage."
} 
and Luther's translation of the Bible into English and German, respectively, Caxton's establishment of printing in England, and Dr. Johnson's dictionary of English published in 1755. Standardization requires that a measure of agreement be achieved about what is in the language and what is not." Codification and standardization are crucial aspects of language policy and language planning. Spolsky (2004) is instructive on the definition of language policy which comprises three components: the language practices of a community; language ideologies; and any specific efforts towards influencing practices via interpretation, planning, and management. According to Rubin and Jernudd (1971), "language planning is a deliberate language change ... focused on problem-solving and ... characterized by the formulation and evaluation of alternatives for solving language problems to find the best (or optimal, most efficient) decision." Standardization of language is important in nationhood because of the potential of language to attract social, economic and political relevance.

\subsection{Language Attitudes}

This is any attitude (positive or negative) that impinges on language. While positive attitudes promote language, negative attitudes destroy it. Scholars use different nomenclatures in the classification of language attitudes. Language attitudes determine the success of language planning in any society. Bosede Sotiloye, cited in Ore Yusuf (1992, pp. 146-147) cites the following as language attitudes:

1. Home Attitudes;

2. Ethnocentric Attitude;

3. Anomie;

4. Bilingual Setting Attitudes.

See Ore Yusuf (1992, pp. 146-147) for insights on these language attitudes.

\subsection{Monolingualism}

Although monolingualism is a rare phenomenon, it refers to the existence of a single language in a speech community.

\subsection{Bilingualism}

This is the existence of two languages in a speech community. According to scholars, there are different types of bilingualism: monocultural co-ordinate bilingual (the monocultural co-ordinate bilingual learns L2 due to its instrumentality); bicultural co-ordinate bilingual (a person is one who gets acculturated by L2); and bicultural compound bilingual (a person who acquires two languages and cultures simultaneously).

\subsection{Multilingualism}

It refers to the presence of many languages in a speech community. Nigeria is an example of a multilingual speech community.

\subsection{Transfer}

This is the positive influence of L1 (mother tongue) on L2 (target language).

\subsection{Interference}

It is the infusion of linguistic features (e.g. phonemes) of one language into another. However, interference can be extra-linguist infusions (cultural norms).

\subsection{Interlarding}

This is also known as code-mixing (using two or more linguistic codes in speech). It can be intra-lingual (stylistic variation) or interlingual (language variation). For example, interlading operates when a speaker of English infuses Yoruba expressions into an on-going speech.

\subsection{Code-switching}

This is when a speaker suddenly shifts from one language (language variation) or style (stylistic variation) to another. Stylistic variation is necessitated by contextual and sociolinguistic variables (underpinnings) such as topic, participants' relationship, etc. On the other hand, language variation is informed by different factors especially insufficient mastery of L2 (foreign or target language).

\section{Discussion and Conclusion}

Sociolinguistics captures the different dimensions that language takes when the different groups in society interact or communicate via language. The situation is essentially the use of language varieties across domains. Bello, O. Rachael and Oni-Buraimoh, O. Olawunmi (2017, p. 103) note that "it is usual for communities to naturally stratify their use of language following certain sociolinguistic variables such as sex, age, religion, profession, etc. Thus, in-groups customarily find common identities and promote these sometimes developing them into codes. This sociolinguistic practice further helps to confirm the unrealistic idea of a global language. The roles that language 
plays exceed that of communication. It is also used for expressing ideas, initiating and maintaining phatic relationships as well as for documenting and passing on the practices of its users. Speech communities have experiences as dictated by their environments and the people with whom they interact...

In a speech community, determining the roles or functions of language is crucial. There are different groups of people who deploy language for different purposes. The literature of sociolinguistics captures theoretical and practical perspectives about language and society. This study is an attempt to underscore language-related variables that determine how a social system operates. Linguists are behavioural scientists, and this posture enables them to elucidate sociolinguistics as an investigation of the relationship that humans have with "language" and "society".

Adeniran, cited in Ayodabo (2013, p. 249), makes an instructive remark on linguists' concerns: "Linguists, whose science must also be seen as primarily a behavioural, one, have not shown sufficient professional interest in the elite as a dynamic group in language development and standardization. Ordinarily, the linguist is aware of differences among people in a community which can be classified on the basis of differences in their speech form and speech style. Indeed, his training equips him to do this almost effortlessly better than the acutely observant person but who has no training in linguistics. But not many linguists try to tolerate the observed differences on the social plane to the perceived differences in speech and take advantage of the correlations of such differences in the analyses of language. Most of the occasions, the linguist is interested only in the generalizable norms of language; he therefore passes the seemingly intractable or uncontrollable variations as most unlikely to have any consequences for his analyses of the norm."

Choice making in the use of language, is indispensable. An overview of sociolinguistics is essentially an investigation into how, why and where people demonstrate their communicative competence in language choice. This submission aligns with that of Ngugi, cited in Otagburuagu (2016, p. 10) who opines that "The choice of language and the use of which language is being put is central to a people's definition of themselves in relation to their natural and social environment, indeed in relation to the entire universe."

Language use in society is a reflection of the dynamics of achieving effective communication at individual and societal levels; this informs the deployment of language varieties (standard, idiolect, sociolect, register, pidgin, etc.) according to situational nuances. Akinnaso (2011) asserts that "communication is said to be effective when the sender's aim or objective of sending a message is achieved by acknowledging, understanding and implementing the message." In a similar vein, Baba (2014) posits that effective communication "involves giving of understandable information, receiving and understanding the message involved to the extent that the intended response is elicited or gotten." People cannot survive the exigencies of local, national and international relationship with their fellow humans without the instrumentality of language. Sociolinguistics underscores this view. Oreoluwa Abraham Solomon and Gbenga Ibileye (2016, p. 138) opine that "language is crucial to the communal existence of man. By means of language, we reach out to distant frontiers and create possibilities that review and sustain human existence. Language is an indispensable asset that man uses to explore and navigate his world." Similarly, Clement Gowon Omachonu, Joseph Abuh and Habiba Oma Alhassan (2017, p. 167) aver that "language principally is human linguistic behavior. Language occupies a prominent position in the affairs of human beings. Despite its crucial role in interpersonal communication and identity formation, it is central in all the activities humans participate in."

This study reveals that language is the pillar behind the social order in society - an order which encapsulates human behaviour along ethnic, national, occupational and other multifaceted lines. It is therefore not surprising that governments plan societal development via the instrumentality of language. M. S. Abdullahi-Idiagbon, cited in Ayodabo et al. (2016, p. 390), opines that "the interference between language and society has long been established. Thus, classification of language into regional, dialectal and discourse varieties are indicative of the sensitivity of language to differences in the society. In view of this, sociolinguists assert that human society is stratified along linguistic and social indices. Language is, thus, seen as a potent apparatus applicable to account for the correlation, between social structure and language behaviour." This submission is in tandem with that of Janet Holmes (2008, p. 1) who notes that "sociolinguists study the relationship between language and society. They are interested in explaining why we speak differently in different social contexts, and they are interested in identifying the social functions of language and the ways it is used to convey social meaning. Examining the way people use language in different social contexts provides a wealth of information about the ways language works, as well as about the social relationships in a community, and the way people signal aspects of sociolinguistic study. The way people talk is influenced by the social context in which they are talking. It matters who can hear us and where we are talking, as well as how we are feeling. The same message may be expressed very differently to different people. We use different styles in different social contexts." 4

So long as sociolinguistics is immersed in explaining who uses language, why, how and where, the sociolinguistic variables that inform language use are crucial. Although we do not discuss them elaborately in this paper, the literature shows that they include: age, ethnicity, class (social status) and gender. The age variable concerns time factor. For example, Oloruntoba-Oju (1999, p. 131) observes that the elderly tend to be conservative in language use. Whether an individual's ethnic affiliation is a product of choice or imposition, ethnicity determines language use. Sociolinguists hold the view that "status" is the most significant variable that determines language

\footnotetext{
${ }^{4}$ The dynamic social nuances that underpin language use are essentially contexts. Janet Holmes (2008, p. 1) also posits that “sociolinguistics is concerned with the relationship between language and the context in which it is used."
} 
use, especially in the spoken medium, where speakers use language to show social ties or prestige. As a sociolinguistic variable affecting language use, gender has to do with linguistic forms that are preferred by males and those preferred by females. Romaine (2003) notes that a major criticism of the general interpretation concerning sex (or gender) and language change (or variation) is the nature of sex categories and the nature of language. $S e x$ is a word used in connection with the biological characteristics that mark humans and other animals as either male or female, whereas gender refers to the cultural traits and behaviors deemed appropriate for men or women by a particular society.

This study examines sociolinguistics from various perspectives to that abound in the literature (concepts and phenomena). Conclusively, the study reveals that sociolinguistics is the theoretical and practical interpretation of the relationship between language and society. Language is made to demonstrate its functional potency in society when the dynamic social nuances that are invoked by the users are brought to the fore. 5

\footnotetext{
${ }^{5}$ Thus, the relationship between language and society remains the focus of research in sociolinguistics.
} 


\section{References}

1. Abiodun, S. (1992). Applied linguistics. In Y. Ore (Ed.), Introduction to linguistics (p. 144). Department of Linguistics and Nigerian Languages, University of Ilorin.

2. Abdullahi-Idiagbon M. S. (2016). The imports of language pattern on social class. In Ayodabo et al. Linguistics, language and literature. Department of English and Literary Studies, Federal University Lokoja.

3. Agha, A., (2006) Registers of language. In A. Duranti (Ed.), A companion to linguistic anthropology. Blackwell.

4. Austin J. L. (1962). How to do things with words. Havard University Press.

5. Ayodabo J. (2013). Linguistic and sociolinguistic situation in Nigeria. Haytee Press.

6. Bello, O. R. \& Oni-Buraimoh, O. O. (2017). A common language upon a non-sectarian human race: A sine qua non for global advancement? JESAN, 19(1): 98.

7. Bennett, J. (1976). Linguistic behaviour. Cambridge University Press.

8. Blake, R. \& Cutler, C. (2003). AAE and variation in Teachers' Attitudes: A question of school philosophy? Linguistics and Education, 14(2): 163-94. https://doi.org/10.1016/s0898-5898(03)00034-2

9. Bosede, S. (1992). Sociolinguistics. In Y. Ore (Ed.), Introduction to linguistics (p. 145). Department of Linguistics and Nigerian Languages, University of Ilorin.

10. Breen, M. (1987). Learners' contribution to task design. In C. Candlin \& D. Murphy (Eds.), Language learning tasks. Englewood Cliffs NJ: Prentice-Hall.

11. Coulmas, F. (1999). The Far East. In J. A. Fishman (Ed.), Handbook of language and ethnic identity. Oxford University Press.

12. Crystal, D. (1971). Linguistics. Harmonsurth: Penguin.

13. Fishman, J. A. (1968). Sociolinguistics and the language problems of developing countries. In J. A. Fishman, C. A. Ferguson, \& D. Gupta (Eds.), Language problems of developing nations. John Wiley \& Sons, Inc.

14. Goodwin, M. H. \& Alim, H. S. (2010). Whatever (neck roll, eye roll, teeth suck) : The situated coproduction of social categories and identity through stancetaking and transmodal styliation. Journal of Linguistic Anthropology, 20(1): 179-94. https://doi.org/10.1111/j.1548-1395.2010.01056.x

15. Harrison, K D. (2007). When language die. Oxford University Press.

16. Heller, M. (2007). Bilingualism: A social approach. Palgrave Macmillan.

17. Holmes, J. (2008). An introduction to sociolinguistics (Third Edition). Pearson Education Limited.

18. Martin P. (Ed.) (1994). Language contact and language conflict. John Benjamins.

19. Naklas M. (Ed.) (1989). Bilingualism and language disability. College Hall Press, Inc.

20. Oloruntoba-Oju, T. (1999). Sociolinguistics: An overview. In Adegbija, (Ed), The English language and literature in English: An introductory handbook. University of Ilorin.

21. Romaine, S. (2003). Variation in language and gender. In J. Holmes and M. Meyerhoff (Eds.), The handbook of language and gender. Blackwell.

22. Searle J. (1969). Speech acts: An essay in the philosophy of language. Cambridge University Press.

23. Smith, J. R. (1969). Language and the total system of communication. In A. H. Archibald (Ed.), Linguistics today. Basic Books.

24. Spolsky, B. (2004). Language policy. Cambridge University Press.

25. Stroud, C. \& Sibonile M. (2009). Towards a material ethnography of linguistic landscape: Multilingualism, mobility and space in a South African township. Journal of Sociolinguistics. 13(3): 363-86. https://doi.org/10.1111/j.14679841.2009.00410.x

26. Wardhaugh, R. \& Fuller J. M. (2015). An Introduction to sociolinguistics. (7th Edition). John Wiley and Sons, Inc.

27. Winford, D. (2003). An introduction to contact linguistics., Blaclwell.

28. Yusuf, O. (Ed.) (1992). Introduction to linguistics. Ilorin: Department of Linguistics and Nigerian Languages, University of Ilorin. 